\title{
The Effect of the Catalyst on the Selectivity of the Heterogeneous 1,4-addition of Organomagnesium Compounds to Chalcone
}

\author{
Kinga Juhász', Zoltán Hell1* \\ ${ }^{1}$ Department of Organic Chemistry and Technology, Faculty of Chemical Technology and Biotechnology, \\ Budapest University of Technology and Economics, H-1521 Budapest, P.O.B. 91, Hungary \\ *Corresponding author, e-mail: zhell@mail.bme.hu
}

Received: 21 February 2019, Accepted: 15 May 2019, Published online: 27 June 2019

\begin{abstract}
The conjugate addition in the presence of a catalytic amount of copper is a widely used method for the formation of a C-C bond. However, mostly homogeneous catalysts and/or homogeneous ligands are used in these type of reactions. Previously we reported the heterogeneous catalytic 1,4-addition of organomagnesium compounds to chalcones in the presence of Cu(II) on $4 \AA$ molecular sieve support. In this study various heterogeneous supported catalysts were tested in the 1,4-addition reaction, such as La(III), Ti(IV), In(III), $\mathrm{Co}(\mathrm{II})$ and $\mathrm{Ni}(\mathrm{II})$ on $4 \AA$ molecular sieve support. Using the Ti(IV)-4A the desired products could be obtained in excellent yields and no 1,2-addition by-product could be detected. Therefore the reusability of the catalyst was tested in a second reaction. It was found, that the Ti(IV)-4A cannot be reused in this type of reaction, due to significant loss of selectivity. In the second experiment a considerable amount of the 1,2-addition product was formed. Thus, the $\mathrm{Cu}(\mathrm{II})$-4A is a suitable catalyst for the heterogeneous 1,4-addition of organomagnesium compounds to chalcones, as described in our previous work.
\end{abstract}

Keywords

heterogeneous catalysis, copper, 1,4-addition, chalcone, organomagnesium compounds

\section{Introduction}

The formation of a C-C bond is a widely researched field of interest in synthetic organic chemistry. One of the most important methods to form a C-C bond is the addition of nucleophiles to electron-deficient conjugated structures. Usually, in the reaction of $\alpha, \beta$-unsaturated carbonyl compounds and organometallic reagents a 1,2-addition occurs. However, in the presence of a catalytic amount of a copper salt 1,4-addition was observed [1-4].

Kharash and Tawney [5] achieved a conjugate addition in the reaction of methylmagnesium bromide and isophorone by adding a catalytic amount of copper chloride to the reaction mixture. In the past few years the reaction was thoroughly examined and a reactivity order of the organometallic reagents was set. Accordingly, the organomagnesium reagents are most likely to react in this kind of reactions [5].

Since the first attempt the transition metal catalysed 1,4-addition was examined thoroughly. In several cases the stereochemistry of the reaction was investigated in the presence of various catalyst ligands [6-8].
There are several articles in the literature, in which 1,4-addition reactions have been carried out in the presence of various metal salts. Pérez et al. [9] reported a nickel-catalysed 1,4-addition reaction of triorganoindium compounds to $\alpha, \beta$-unsaturated systems. The reactivity of several nickel complexes was investigated and the $\mathrm{Ni}(\mathrm{COD})_{2}$ complex was found to give the best results. The 1,4-addition products were obtained in a yield of $80 \%$ [9].

An Italian research group investigated the conjugate addition of indoles and thiols to $\alpha, \beta$-unsaturated ketones, using indium(III) bromide as catalyst. Followed by a 1,2-addition of trimethylsilylcyanide they were able to prepare the corresponding $\beta$-indolyl-ketones, which can be interesting building blocks of biologically active compounds and natural products [10].

On the other hand, Kelly and Gilheany [11] found, that in the conjugate addition of organomagnesium reagents to $\alpha, \beta$-unsaturated carbonyl compounds $\mathrm{InCl}_{3}$ promoted the 1,2-addition. The reaction was carried out using multiple 
carbonyl compounds, and in some cases the 1,2-addition product could be obtained selectively [11].

However, the major problem of these reactions is that they use homogeneous catalysis and/or homogeneous ligands. After the reaction the separation of these catalysts and ligands from the reaction mixture can be tedious. The separation of a heterogeneous catalyst is generally easier, thus we examined the conjugate addition using heterogeneous catalysts.

\section{Results and discussion}

Recently, we reported a heterogeneous catalytic method for the addition of organomagnesium compounds to chalcones in the presence of copper(II) on $4 \AA$ molecular sieve support $[\mathrm{Cu}(\mathrm{II})-4 \mathrm{~A}]$. The reaction afforded the desired products in good yields and no by-product could be observed [12].

In continuation of our interest we examined the reaction of ethylmagnesium iodide (2) and chalcone (1) in the presence of various heterogeneous catalysts. We aimed to investigate the effect of the applied catalysts on the selectivity of the 1,4-addition. Different metals [La(III), Ti(IV), In(III), Co(II), Ni(II)] on $4 \AA$ molecular sieves were used as catalysts. The results are summarized in Table 1 . The efficiency of the non-impregnated molecular sieves was also tested. In all cases the 1,4-addition product (3) was the major product and the 1,2-addition product could not be detected. However, in the case of the In(III)-, Co(II)- and $\mathrm{Ni}(\mathrm{II})-4 \mathrm{~A}$ catalysts another by-product (4) was observed in the GC-MS spectra of the crude products (Fig. 1). This can be formed in the reaction of the desired product (3) with another chalcone molecule (1) in an aldol-type reaction. When the La(III)-4A catalyst was used, no by-product could be observed on the ${ }^{1} \mathrm{H}$ NMR and GC-MS spectra, but the yield remained significantly lower, than in the cases of the $\mathrm{Cu}(\mathrm{II})-$ and $\mathrm{Ti}(\mathrm{IV})-4 \mathrm{~A}$ catalysts.

Besides the already reported $\mathrm{Cu}(\mathrm{II})-4 \mathrm{~A}$, the Ti(IV)-4A appeared to be efficient in the conjugate addition reaction. The desired product (3) could be obtained with a yield of $80 \%$ in both reactions. Therefore the reaction of phenylmagnesium iodide (5) with chalcone was also examined in the presence of Ti(IV)-4A and the desired conjugate addition product (6) was obtained in excellent yield. The results are presented in Table 2. Using Ti(IV)-4A as the catalyst, in the reaction of phenylmagnesium iodide (5) and chalcone (1) the 1,4-addition product (6) was obtained in a yield of $90 \%$. Therefore it seems, that the Ti(IV)-4A is also a suitable catalyst for the conjugate addition of arylmagnesium halides.
Table 1 Reaction of ethylmagnesium iodide (2) with chalcone (1) in the presence of various catalysts

\begin{tabular}{lcc}
\hline Entry & Catalyst & $\begin{array}{c}\text { Yield }^{\mathrm{a}} \\
\mathbf{( \% )}\end{array}$ \\
\hline 1. & $\mathrm{Cu}(\mathrm{II})-4 \mathrm{~A}$ & 80 \\
2. & $\mathrm{La}(\mathrm{III})-4 \mathrm{~A}$ & 67 \\
3. & $\mathrm{Ti}(\mathrm{IV})-4 \mathrm{~A}$ & 80 \\
4. & $\mathrm{In}(\mathrm{III})-4 \mathrm{~A}$ & 80 \\
5. & $\mathrm{Co}(\mathrm{II})-4 \mathrm{~A}$ & 70 \\
6. & $\mathrm{Ni}(\mathrm{II})-4 \mathrm{~A}$ & 75 \\
\hline
\end{tabular}

$2 \mathrm{mmol}$ magnesium, $2.3 \mathrm{mmol}$ ethyl iodide, $1 \mathrm{mmol}$ chalcone, $0.1 \mathrm{~g}$ catalyst, $9 \mathrm{~mL}$ diethyl ether, reflux temperature, $6 \mathrm{~h}$

a Isolated yield, the purity is checked by GC-MS

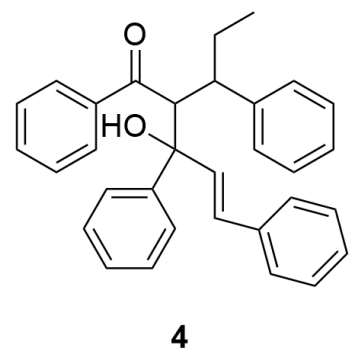

Fig. 1 The by-product identified by GC-MS

Table 2 Examination of the applicability of the Ti(IV)-4A catalyst in the reaction of various organomagnesium halides ( 2 or $\mathbf{5}$ ) with chalcone (1)

\begin{tabular}{lccc}
\hline Entry & R-MgX & $\begin{array}{c}\text { Yield with Cu(II)-4A } \\
(\%)^{\mathrm{a}}\end{array}$ & $\begin{array}{c}\text { Yield with Ti(IV)-4A } \\
(\%)^{\mathrm{a}}\end{array}$ \\
\hline 1. & 80 & 80 \\
& & & \\
2. & & 83 & 90 \\
\hline
\end{tabular}

$2 \mathrm{mmol}$ magnesium, $2.3 \mathrm{mmol}$ alkyl/aryl halide, $1 \mathrm{mmol}$ chalcone, $0.1 \mathrm{~g}$ catalyst, $9 \mathrm{~mL}$ diethyl ether, reflux temperature, $6 \mathrm{~h}$

${ }^{\text {a }}$ Based on GC-MS

In order to demonstrate the need for the metal catalysis, the reaction was carried out in the presence of pure $4 \AA \AA$ molecular sieves. Based on the GC-MS spectra it can be concluded, that the desired product (3) was formed in the reaction with high yield, but the ${ }^{1} \mathrm{H}$ NMR spectrum showed the presence of several by-products, which were not formed in the metal catalysed reactions. These by-products could not be separated from the product.

After the thorough investigation of the effect of the catalyst on the 1,4-addition reaction we wished to examine the recyclability and reusability of the catalyst. In our previous report the reusability of the $\mathrm{Cu}$ (II)-4A was described [12]. Besides the $\mathrm{Cu}(\mathrm{II})-4 \mathrm{~A}$ the Ti(IV)-4A was found to be an efficient catalyst in the conjugate addition 
of organomagnesium halides to chalcone (1). Therefore, the reusability of the $\mathrm{Ti}(\mathrm{IV})-4 \mathrm{~A}$ was tested in the reaction of ethylmagnesium iodide (2) with chalcone (1). After the completion of the reaction the catalyst was filtered from the reaction mixture, washed with acetone and dried at $120^{\circ} \mathrm{C}$ for $1 \mathrm{~h}$. Then it was used in a second experiment. On the ${ }^{1} \mathrm{H}$ NMR spectrum of the crude product several by-products could be detected, which were not formed in the first reaction. In the second reaction with the Ti(IV)-4A a significant amount of the 1,2-addition product was formed as well. Therefore it can be concluded, that the Ti(IV)-4A catalyst cannot be reused in the heterogeneous catalytic conjugate addition reaction (Table 3 ).

The products were subjected to an XRF analysis to check the leaching of the metals from the surface of the catalysts. In accord with the results obtained earlier [13], no appreciable amount of metal could be detected. This means that the leaching of the metal during the reaction is negligible.

\section{Experimental}

\subsection{General methods}

GC-MS measurements were performed on an Agilent 6890N-GC-5973N-MSD chromatograph, using a $30 \mathrm{~m} \times 0.25 \mathrm{~mm}$ Restek, Rtx-5SILMS column with a film layer of $0.25 \mu \mathrm{m}$. The initial temperature of column was $45^{\circ} \mathrm{C}$ for $1 \mathrm{~min}$, followed by programming at $10{ }^{\circ} \mathrm{C} / \mathrm{min}$ up to $310^{\circ} \mathrm{C}$ and a final period at $310^{\circ} \mathrm{C}$ (isothermal) for $17 \mathrm{~min}$. The temperature of the injector was $250^{\circ} \mathrm{C}$. The carrier gas was $\mathrm{He}$ and the operation mode was splitless. ${ }^{1} \mathrm{H}$ NMR spectra were made on BRUKER Avance-300 instrument using TMS as an internal standard in $\mathrm{CDCl}_{3}$.

All reagents and solvents were purchased from Merck Hungary Ltd.

\subsection{Preparation and characterization of the catalysts}

A suspension of $4 \AA$ molecular sieves (2 g) in deionized water $(200 \mathrm{~mL})$ containing $2 \mathrm{mmol}$ of the metal salt $\left(\mathrm{CuCl}_{2} * 2 \mathrm{H}_{2} \mathrm{O}, \quad \mathrm{La}\left(\mathrm{NO}_{3}\right)_{2} * 6 \mathrm{H}_{2} \mathrm{O}, \quad \mathrm{TiCl}_{4}, \mathrm{In}\left(\mathrm{NO}_{3}\right)_{3} * \mathrm{H}_{2} \mathrm{O}\right.$, $\left.\mathrm{CoCl}_{2} * 6 \mathrm{H}_{2} \mathrm{O}, \mathrm{NiCl}_{2} * 6 \mathrm{H}_{2} \mathrm{O}\right)$ was stirred for $12 \mathrm{~h}$ at room temperature. The solid was filtered, washed with deionized water $(50 \mathrm{~mL})$ and acetone $(20 \mathrm{~mL})$, then dried in an oven at $120^{\circ} \mathrm{C}$ for $1 \mathrm{~h}$. The metal content was determined by ICP-OES (see Table 4). The original surface area of the molecular sieves $\left(810 \mathrm{~m}^{2} / \mathrm{g}\right)$ dropped after the impregnation. During the impregnation metal ions can replace the sodium ions in the synthetic microporous sodium aluminosilicate. Energy-Dispersive X-ray Spectroscopy (EDS) showed that metals evenly covered the support's surface.
Table 3 Investigation of the reusability of the catalysts

\begin{tabular}{lcc}
\hline \multirow{2}{*}{ Number of uses } & \multicolumn{2}{c}{ Yield (\%) } \\
& Cu(II)-4A & Ti(IV)-4A \\
\hline 1 & 80 & 80 \\
2 & 79 & 60 \\
\hline
\end{tabular}

Table 4 Characterization of the catalysts

\begin{tabular}{lccc}
\hline Entry & Catalyst & $\begin{array}{c}\text { Metal content } \\
(\mathbf{w t} \%)\end{array}$ & $\begin{array}{c}\text { Surface area } \\
\left(\mathbf{m}^{\mathbf{2}} \mathbf{g} \mathbf{)}\right.\end{array}$ \\
\hline 1. & $\mathrm{Cu}(\mathrm{II})-4 \mathrm{~A}$ & 5.80 & 360 \\
2. & $\mathrm{La}(\mathrm{III})-4 \mathrm{~A}$ & 3.88 & 35 \\
3. & $\mathrm{Ti}(\mathrm{IV})-4 \mathrm{~A}$ & 3.99 & 122 \\
4. & $\mathrm{In}(\mathrm{III})-4 \mathrm{~A}$ & 10.20 & 30 \\
5. & $\mathrm{Co}(\mathrm{II})-4 \mathrm{~A}$ & 4.98 & 270 \\
6. & $\mathrm{Ni}(\mathrm{II})-4 \mathrm{~A}$ & n.d. & n.d. \\
\hline
\end{tabular}

a Not determined

Surface analysis by scanning electron microscope (SEM) showed that the zeolite crystals retained their cubic form.

\subsection{General procedure for the preparation of compounds 3 and 6}

Compounds 3 and $\mathbf{6}$ were synthesized according to our previous report [10].To the mixture of magnesium $(0.05$ $\mathrm{g}, 2 \mathrm{mmol}$ ) and $3 \mathrm{~mL}$ of diethyl ether the solution of the corresponding halide $(2.3 \mathrm{mmol})$ in diethyl ether $(3 \mathrm{~mL})$ was added. After the formation of the corresponding Grignard-reagent ( $\mathbf{2}$ or $\mathbf{5}$ ) the catalyst was added. Then the solution of the chalcone $(0.21 \mathrm{~g}, 1 \mathrm{mmol})$ in diethyl ether was added dropwise. The reaction mixture was stirred for $6 \mathrm{~h}$ at $35^{\circ} \mathrm{C}$, then quenched with water. The catalyst was filtered off and washed with diethyl ether. The layers were separated and the aqueous layer was washed with diethyl ether. The combined organic phase was dried over anhydrous sodium sulfate and the solvent was evaporated. The crude product was examined by ${ }^{1} \mathrm{H}$ NMR and GC-MS.

1,3-diphenyl-1-pentanone (3) [14]: ' H NMR (300 MHz, $\left.\mathrm{CDCl}_{3}\right) \delta=0.80(\mathrm{t}, 3 \mathrm{H}) ; 1.58-1.87(\mathrm{~m}, 2 \mathrm{H}) ; 3.20-3.32(\mathrm{~m}$, $3 \mathrm{H}) ; 7.12-7.57$ (m, 8H); 7.90 (d, 2H).

1,3,3-triphenyl-1-propanone (6) [15]: ${ }^{1} \mathrm{H}$ NMR (300 $\left.\mathrm{MHz}, \mathrm{CDCl}_{3}\right) \delta=3.79(\mathrm{~d}, 2 \mathrm{H}) ; 4.89(\mathrm{t}, 1 \mathrm{H}) ; 7.18-7.69(\mathrm{~m}$, $13 \mathrm{H}) ; 7.99$ (d, 2H).

\subsection{The reusability of the $\mathrm{Ti}(\mathrm{IV})-4 \mathrm{~A}$ catalyst}

The catalyst used in a previous reaction was washed with acetone and dried at $120^{\circ} \mathrm{C}$ for $1 \mathrm{~h}$. Then the catalyst was used in another reaction of ethylmagnesium iodide (2) and chalcone (1). The reaction was carried out according to General procedure. 


\section{Conclusion}

Besides $\mathrm{Cu}(\mathrm{II})-4 \mathrm{~A}$ Ti(IV)-4A was also found to be an efficient heterogeneous catalyst in the conjugate addition reaction of organomagnesium halides to chalcone. The

\section{References}

[1] Schinzer, D. "Conjugate Addition Reactions in Organic Synthesis. (Reihe: Tetrahedron Organic Chemistry Series, Vol. 9, Reihenherausgeber: J. E. Baldwin.) Von P. Perlmutter. Pergamon, Oxford, 1992. XIX, 373 S., ISBN 0-08-0370675 (Broschur), 0-080370667 (geb.)", Angewandte Chemie, 105(11), pp. 1738-1739, 1993.

https://doi.org/10.1002/ange.19931051144

[2] Polet, D., Alexakis, A. "Copper-catalyzed enantioselective conjugate addition", In: Rappoport, Z., Marek, I. (eds.) The Chemistry of Organocopper Compounds, Wiley, Chichester, UK, 2009, pp. 603-692.

[3] Lipshutz, B. H., Sengupta, S. "Organocopper Reagents: Substitution, Conjugate Addition, Carbo/Metallocupration, and Other Reactions", In: Paquette, L. A. (ed.) Organic Reactions, Vol. 41, Wiley, Hoboken, NJ, USA, 1992, 41, pp. 135-631.

[4] Ortiz, P., Lanza, F., Harutyunyan, S. R. "1,2- Versus 1,4-Asymmetric Addition of Grignard Reagents to Carbonyl Compounds", In: Harutyunyan, S. (eds.) Progress in Enantioselective $\mathrm{Cu}(\mathrm{I})$-catalyzed Formation of Stereogenic Centers. Topics in Organometallic Chemistry, Vol. 58. Springer, Cham, 2016, pp. 99-134. https://doi.org/10.1007/3418_2015_164

[5] Kharasch, M. S., Tawney, P. O. "Factors Determining the Course and Mechanisms of Grignard Reactions. II. The Effect of Metallic Compounds on the Reaction between Isophorone and Methylmagnesium Bromide", Journal of the American Chemical Society, 63(9), pp. 2308-2316, 1941. https://doi.org/10.1021/ja01854a005

[6] Alexakis, A., Bäckvall, J.-E., Krause, N., Pàmies, O., Diéguez, M. "Enantioselective Copper-Catalyzed Conjugate Addition and Allylic Substitution Reactions", Chemical Reviews, 108(8), pp. 2796-2823, 2008. https://doi.org/10.1021/cr0683515

[7] Harutyunyan, S. R., den Hartog, T., Geurts, K., Minnaard, A. J., Feringa, B. L. "Catalytic Asymmetric Conjugate Addition and Allylic Alkylation with Grignard Reagents", Chemical Reviews, 108(8), pp. 2824-2852, 2008.

https://doi.org/10.1021/cr068424k

[8] Jerphagnon, T., Pizzuti, M. G., Minnaard, A. J., Feringa, B. L. "Recent advances in enantioselective copper-catalyzed 1,4-addition", Chemical Society Reviews, 38, pp. 1039-1075, 2009. https://doi.org/10.1039/B816853A desired 1,4-addition products were obtained in high yields after a simple workup of the reaction mixture. However the Ti(IV)-4A catalyst cannot be reused in the reaction due to loss of selectivity towards the 1,4-addition product.

[9] Pérez, I., Pérez Sestelo, J., Maestro, M. A., Mouriño, A., Sarandeses, L. A. "First Nickel-Catalyzed 1,4-Conjugate Additions to $\alpha, \beta$-Unsaturated Systems Using Triorganoindium Compounds", Journal of Organic Chemistry, 63(26), pp. 10074-10076, 1998. https://doi.org/10.1021/jo981830m

[10] Bandini, M., Cozzi, P. G., Giacomini, M., Melchiorre, P., Selva, S., Umani-Ronchi, A. "Sequential One-Pot $\mathrm{InBr}_{3}$-Catalyzed 1,4then 1,2-Nucleophilic Addition to Enones", Journal of Organic Chemistry, 67(11), pp. 3700-3704, 2002. https://doi.org/10.1021/jo0163243

[11] Kelly, B. G., Gilheany, D. G. "Effect of $\mathrm{InCl}_{3}$ on the addition of Grignard reagents to $\alpha, \beta$-unsaturated carbonyl compounds", Tetrahedron Letters, 43(5), pp. 887-890, 2002. https://doi.org/10.1016/S0040-4039(01)02263-8

[12] Juhász, K., Hell, Z. "Heterogeneous catalytic 1,4-addition of arylmagnesium compounds to chalcones", Tetrahedron Letters, 59(32), pp. 3136-3138, 2018.

https://doi.org/10.1016/j.tetlet.2018.07.016

[13] Fodor, A., Kiss, Á., Debreczeni, N., Hell, Z., Gresits, I. "A simple method for the preparation of propargylamines using molecular sieve modified with copper(II)", Organic \& Biomolecular Chemistry, 8(20), pp. 4575-4581, 2010. https://doi.org/10.1039/c0ob00224k

[14] Zhang, L., Yang, G., Shen, C., Arghib, S., Zhang, W. "Chiral dinuclear phthalazine bridged bisoxazoline ligands: synthesis and application in enantioselective $\mathrm{Cu}$-catalyzed conjugate addition of $\mathrm{ZnEt}_{2}$ to enones", Tetrahedron Letters, 52(18), pp. 2375-2378, 2011. https://doi.org/10.1016/j.tetlet.2011.02.098

[15] He, P., Lu, Y., Hu, Q.-S. "Phosphinite- and phosphite-based type I palladacycles as highly active catalysts for addition reactions of arylboronic acids with aldehydes, $\alpha, \beta$-unsaturated ketones, $\alpha$-ketoesters, and aldimines", Tetrahedron Letters, 48(30), pp. 5283-5288, 2007. https://doi.org/10.1016/j.tetlet.2007.05.119 